\title{
Occurrence and In Vitro Antifungal Susceptibility of Candida Spp. Isolated from Decayed Tree Parts in Green Urban Areas from Pisa (Central Italy)
}

\author{
Simona Nardoni*, Valentina Sorrentino and Francesca Mancianti \\ Department of Veterinary Sciences, Italy \\ *Corresponding author: Simona Nardoni, Department of Veterinary Sciences, Italy
}

\section{ARTICLE INFO}

Received: 幽 July 09, 2019

Published: 慧 July 17, 2019

Citation: Simona Nardoni, Valentina S, Francesca M. Occurrence and In Vitro Antifungal Susceptibility of Candida Spp. Isolated from Decayed Tree Parts in Green Urban Areas from Pisa (Central Italy). Biomed J Sci \& Tech Res 19(4)2019. BJSTR. MS.ID.003347.

Keywords: Yeasts; Decaying Trees; Candida Famata; Candida Guilliermondii; Candida Membranaefaciens; Candida Parapsilosis; Antimycotic Drugs; In Vitro Sensitivity

\begin{abstract}
Trees and grass are proven sources of potentially pathogenic yeasts. Among fungi regarded as human/animal pathogens, several Candida Spp. are involved. Since wooded areas are frequented by people and their pets, aim of the present study was to investigate the occurrence of potentially pathogenic yeasts on decaying vegetal material from trees in 2 city parks in Pisa, Italy. A total of 186 samples was collected. The antimycotic drug sensitivity pattern of cultured Candida spp. was evaluated versus fluconazole, voriconazole, caspofungin and amphotericin B, by Etest. Sixteen trees out of 31 (51.6\%) scored positive for yeasts, and twenty-six fungal isolates were cultured. Thermotolerant strains, such as Candida Famata (6/6), Candida Guilliermondii (4/4), Candida Membranaefaciens (2/3) and Candida Parapsilosis (1/1), were obtained. All the yeasts were sensitive to amphotericin B, 2 C. Famata were resistant to assayed azoles, and this fungal species was the only one susceptible to caspofungin, while fluconazole was effective versus all C. Guillermondii isolates. Although the relatively small sample size, decaying vegetal material from trees growing in sampled recreational green areas, would seem to be a natural site harboring potentially pathogens yeasts, characterized by low sensitivity against some important antimycotic drugs.
\end{abstract}

\section{Introduction}

Yeasts can act as important pathogens both in animals and humans and it is well known that most of them occur as saprophytes in the environment, being able to grow on not viable organic matter. Moreover, these organisms are frequently able to form biofilms [1] and some among them are characterized by intrinsic and/ or acquired resistance to one or more commonly administered antifungal drugs [2]. Among fungi regarded as human and animal pathogens, several Candida spp. are reported. Candida Albicans represents the main causative agent for human candidiasis, although the numerous non-albicans species have increased their occurrence in candidiasis in the last decades to $>50 \%$ of bloodstream infections throughout the world [3]. Droppings of domestic as well as free ranging birds are proven sources of potentially pathogenic yeasts [4-7], such as decomposing plant material, trees and grass [8]. For instance, Cryptococcus neoformans and Cryptococcus gattii have been cultured from decaying vegetal materials [9-11], while several other yeasts would dwell onto different trees.
In particular Candida tropicalis, Candida parapsilosis and C. albicans have been recovered from trees [12-14] as well as woodland are considered a privilegiate site for Saccharomyces spp. [15]. Furthermore, wooded and green areas are visited by large numbers of people and their pets, and in the last years reports of mycoses caused by yeasts, mostly referring to fungi belonging to Candida genus, are more frequently encountered than in the past $[2,3,16,17]$. For these reasons, considered also the increased occurrence of immunocompromised patients, the knowledge of the ecology of these fungal species may be of interest. To the best of our knowledge, there are no reports about the presence of yeast species, in particular Candida spp., associated with trees in Italy. Therefore, aim of the present study was to investigate the occurrence of potentially pathogenic yeasts on decaying vegetal material from trees in 2 city parks in Pisa, Italy, evaluating also the drug sensitivity pattern of Candida spp. isolated versus some among the most common used antifungals in human medicine. 


\section{Materials and Methods}

Specimens were drawn from trees growing in 2 green recreational areas, within the urban area of Pisa $\left(43^{\circ} 42^{\prime} 30^{\prime \prime} \mathrm{N} 10^{\circ}\right.$ $24^{\prime} 12^{\prime \prime} \mathrm{E}$ ), Central Italy, visited by both people and pet dogs. Thirtyone trees were sampled. In detail 6 Pinus pinea, 4 Tilia platyphyllos, 1 Platanus acerifolia, 1 Fagus sylvatica, 1 Chicas revoluta and 1 Taxus baccata from site 1, and 4 P. pinea, 2 Salix babylonica, $1 P$. acerifolia, 3 Quercus ilex, 1 Chamaciparis lawsoniana, 1 Morus alba, 1 Laurus nobilis, 1 Nerium oleander, 1 Carpinus betulus and 1 Gleditsia triachantos from site 2, respectively, were selected. Only decaying parts of trees were selected and for each tree roots, tree hollows and leaves were sampled by swabbing technique, as reported by Maganti et al. [12]. For each sampled site 2 swabs were drawn, obtaining 186 total specimens. All samples were immediately transferred to the laboratory and therefore seeded onto Malt Extract Agar (MEA) supplemented with $0.1 \%$ byphenil. Subsequently, they were incubated at both $25^{\circ} \mathrm{C}$ and $37^{\circ} \mathrm{C}$, until a noticeable fungal growth was ascertained. The latter temperature was selected in order to evaluate the thermotolerance of isolates. Yeast identification was achieved by microscopic analysis, as well as auxanographic profile using ID32C galleries (BioMérieux, Marcy l'Etoile, France). All strains presumptively referring to Candida genus were subsequently subjected to PCR analysis, performed by amplification and partial sequencing of the D1/D2 domain of 26S rRNA encoding gene, as described by Lopandic et al. [18], as confirmatory identification test. DNA partial sequences obtained were then compared with those present in the NCBI database, by matching the BLAST program from GenBank. Sequences with a 98 to $100 \%$ identity with GenBank sequences were retained as significant for the molecular identification of yeasts. Candida spp. sensitivity to most frequently employed antimycotic drugs (amphotericin B, fluconazole, voriconazole, caspofungin) was evaluated by Etest (BioMérieux, Marcy l'Etoile, France). Minimal inhibition concentrations (MIC) breakpoints, when available, were calculated following the CLSI recommendations for Candida spp. [19]. For amphotericin B this value is not available, so the antifungal clinical breakpoint provided by EUCAST was considered [20].

\section{Results}

Sixteen trees out of 31 (51.6\%) scored positive for yeasts in at least one sampled site. Twenty-six fungal isolates were cultured and identified as Candida spp., Debaryomyces polymorphus, Rhodotorula sp. and Pichia etchelsii. In particular, thermotolerant Candida isolates were obtained for Candida famata (6/6), Candida guilliermondii (4/4), Candida membranaefaciens (2/3) and Candida parapsilosis (1/1). Eight $P$. pinea out of 10 scored positive, with Candida spp. as the most prevalent genus, recovered from at least 1 site. Candida spp. were isolated from 1 T. platyphyllos, $2 \mathrm{~S}$. babylonica, $1 \mathrm{C}$. lawsoniana and $1 \mathrm{~L}$. nobilis. Different fungal species from the same tree were detected in 3 P. pinea, 1 T. platyphyllos and 1 P. acerifolia. PCR analysis confirmed in all cases the presumptive Candida species identification based on phenotypic features, showing a high similarity (>99\%) with the deposit species sequences described in the GenBank database determined by BLAST. Cryptococcus neoformans/gattii was never been isolated during the study. All Candida isolates were sensitive to amphotericin B, 2 C. famata were resistant to all azoles assayed, while fluconazole was effective versus all C. guillermondii isolates. Interestingly, $C$. famata was the sole yeast species fully sensitive to caspofungin. More detailed data about the source of yeasts and drug sensitivity pattern are reported.

\section{Discussion}

The fungal species isolated are in agreement with the findings of Maganti et al. [12], who report the occurrence of Candida, Rhodotorula and Pichia Genera from tree hollows in urban areas. A limitation of this study is the low number of sampled trees, indeed. Unfortunately, it was not possible to overpass this problem, since the study design was focused on decaying trees only, that were present in low numbers in sampled areas. Among Candida spp., $C$. parapsilosis is an important etiological agent of invasive candidiasis [21], representing the second or third most common species isolated in human candidemia worldwide. The isolate obtained in our study showed resistance to fluconazole and caspofungin. These findings agree with literature data, and the fluconazole resistance of some strains within this yeast species has been related to an overexpression of MRR1 [22]. C. famata was the most prevalent recovered yeast species and it is considered as a rare, but emergent [23] cause of candidiasis, with a prevalence ranging from $0.2 \%$ to $2 \%$ [24]. These yeasts have been reported as agents associated to urinary tract infection in pets, characterized by similar antimycotic drugs sensitivity patterns [25]. In the present study, 5 out of 6 isolates were resistant to fluconazole, while the other one had a dose dependent sensitivity. Moreover, 2 isolates resulted resistant to voriconazole. This finding would appear of interest, showing that isolates characterized by high rates of resistance would be widely spread in urban environment. C. guilliermondii has been reported as a cause of candidemia in neoplastic patients [26], being involved in up to $2 \%$ of human cases [27], and in a joint infection in a dog [16]. Three out of 4 strains scored resistant to caspofungin, while the other one showed intermediate sensitivity, in agreement with Marcos-Zambrano et al. [27]. C. membranaefaciens is a yeast infrequently reported in intravenous catheter-associated invasive infections [28,29], whose sensitivity to fluconazole is a matter of debate [28]. The isolates obtained in our work seem to confirm the resistance to fluconazole. The intermediate sensitivity of all the three isolates to caspofungin appears to be an interesting finding. The results obtained from this study would indicate that decaying vegetal material from trees occurring in investigated recreational green areas, seems to harbor potentially pathogen yeasts, characterized by low sensitivity against some currently used antimycotic drugs.

\section{Disclosure of Interest}

The authors declare no conflict of interest. 


\section{References}

1. El Azizi M, Farag N, Khardori N (2015) Antifungal activity of amphotericin B and voriconazole against the biofilms and biofilm dispersed cells of Candida albicans employing a newly developed in vitro pharmacokinetic model. Ann Clin Microbiol Antimicrob 14: 21.

2. Lamoth F, Lockhart SR, Berkow EL, Calandra T (2018) Changes in the epidemiological landscape of invasive candidiasis. J Antimicrob Chemother 73(1): i4-i13.

3. Arendrup MC, Patterson TF (2017) Multidrug resistant Candida epidemiology, molecular mechanisms, and treatment. J Infect Dis 216(3): 445-451.

4. Mancianti F, Nardoni S, Ceccherelli R (2002) Occurrence of yeasts in psittacines droppings from captive birds in Italy. Mycopathologia 153(3): 121-124.

5. Subramanya SH, Sharan NK, Baral BP, Hamal D, Nayak N, et al. (2017) Diversity, in-vitro virulence traits and antifungal susceptibility pattern of gastrointestinal yeast flora of healthy poultry, Gallus gallus domesticus. BMC Microbiol 17: 113.

6. Brilhante RSN, Silva ALD, Monteiro FOB, Guedes GMM, Sales JA, et al. (2017) Yeasts from Scarlet ibises (Eudocimus ruber): a focus on monitoring the antifungal susceptibility of Candida famata and closely related species. Med Mycol 55(7): 725-732.

7. Simi WB, Leite Jr DP, Paula CR, Hoffmann Santos HD, Takahara DT, et al. (2018) Yeasts and filamentous fungi in psittacidae and birds of prey droppings in midwest region of Brazil: a potential hazard to human health. Braz J Biol.

8. Cadete RM, Lopes MR, Rosa CA (2017) Yeasts associated with decomposing plant material and rotting wood. In: Buzzini P, Lachance MA, Yuokov A, (Eds.), Yeasts in natural ecosystems: diversity. Springer International Publishing pp. 265-292.

9. Cogliati M, D Amicis R, Zani A, Montagna MT, Caggiano G, et al. (2016) Environmental distribution of Cryptococcus neoformans and C. gattii around the Mediterranean basin. FEMS Yeast Res 16(4): 045.

10. Mseddi F, Sellami A, Jarboui MA, Sellami H, Makni F, et al. (2011) First environmental isolations of Cryptococcus neoformans and Cryptococcus gattii in Tunisia and review of published studies on environmental isolations in Africa. Mycopathol 171(15): 355-360.

11. Cattana ME, Sosa Mde L, Fernández M, Rojas F, Mangiaterra M, et al. (2014) Native trees of the Northeast Argentine: natural hosts of the Cryptococcus neoformans-Cryptococcus gattii species complex. Rev Iberoam Micol 31(3): 188-192.

12. Maganti H, Bartfai D, Xu J (2012) Ecological structuring of yeasts associated with trees around Hamilton, Ontario, Canada. FEMS Yeast Res 12(1): 9-19.

13. Carvalho C, Yang J, Vogan A, Maganti H, Yamamura D, et al. (2014) Clinical and tree hollow populations of human pathogenic yeast in Hamilton, Ontario, Canada are different. Mycoses 57(5): 271-283.

14. Bensasson D, Dicks J, Ludwig JM, Bond CJ, Elliston A, et al. (2018) Diverse lineages of Candida albicans live on old oaks. Genetics 211(1): 277-288.

\section{ISSN: 2574-1241}

DOI: 10.26717/BJSTR.2019.19.003347

Simona Nardoni. Biomed J Sci \& Tech Res

This work is licensed under Creative Commons Attribution 4.0 License

Submission Link: https://biomedres.us/submit-manuscript.php
15. Eberlein C, Leducq JB, Landry CC (2015) The genomics of wild yeast populations sheds light on the domestication of man's best (micro) friend. Molec Ecol 24(21): 5309-5311.

16. Bufalari A, Maggio C, Moretti G, Crovace A, Stefanetti V, et al. (2016) Management of Candida guilliermondii joint infection in a dog. Acta Vet Scand 8: 47

17. Cordeiro RA, Sales JA, Castelo-Branco DSCM, Brilhante RSN, Ponte YB, et al. (2017) Candida parapsilosis complex in veterinary practice: A historical overview, biology, virulence attributes and antifungal susceptibility traits. Vet Microbiol 212: 22-30.

18. Lopandic K, Zelger S, Banszky LK, Eliskases-Lechner F, Prillinger H (2006) Identification of yeasts associated with milk products using traditional and molecular techniques. Food Microbiol 23(4): 341-350.

19. (2017) Clinical and Laboratory Standard Institute (CLSI) Performance standards for antifungal susceptibility testing of yeasts. $\left(1^{\text {st }}\right.$ edn.). CLSI: Wayne, PA, USA, p. M60.

20.(2019) European Committee on antimicrobial susceptibility testing (EUCAST): clinical breakpoints and dosing of antibiotics.

21. Papp C, Kocsis K, Toth R, Bodai L, Willis JR, et al. (2018) Echinocandininduced microevolution of Candida parapsilosis influences virulence and abiotic stress tolerance. mSphere 3(6).

22. Zhang L, Xiao M, Watts MR, Wang H, Fan X, et al. (2015) Development of fluconazole resistance in a series of Candida parapsilosis isolates from persistent candidemia patient with prolonged antifungal therapy. BMC Infect Dis 15: 340 .

23. Diba K, Makhdoomi K, Nasri E, Vaezi A, Javidnia J, et al. (2018) Emerging Candida species isolated from renal transplant recipients: species distribution and susceptibility profiles. Microb Pathog 125: 240-245.

24. Beyda ND, Chuang SH, Alam MJ, Shah DN, Ng TM, et al. (2013) Treatment of Candida famata bloodstream infections: case series and review of the literature. J Antimicrob Chemother 68(2): 438-643.

25. Ebani VV, Nardoni S, Bertelloni F, Pistelli L, Mancianti F, et al. (2018) Antimicrobial Activity of Five Essential Oils against Bacteria and Fungi Responsible for Urinary Tract Infections. Molecules 23(7).

26. Savini V, Catavitello C, Onofrillo D, Masciarelli G, Astolfi D, et al. (2011) What do we know about Candida guilliermondii? A voyage throughout past and current literature about this emerging yeast. Mycoses 54(5): 434-441.

27. Marcos-Zambrano LJ, Puig-Asensio M, Pérez-García F, Escribano P, Sánchez-Carrillo C, et al. (2017) Candida guilliermondii complex is characterized by high antifungal resistance but low mortality in 22 cases of candidemia. Antimicrob Agents Chemother 61(7).

28. Fanci R, Pecile P(2005) Central venous catheter-related infection due to Candida membranaefaciens, a new opportunistic azole-resistant yeast in a cancer patient: a case report and a review of literature. Mycoses 48(5): 357-359.

29. Marín Martínez EM, Aller García AI, Martín-Mazuelos E (2016) Epidemiology, risk factors and in vitro susceptibility in candidaemia due to non-Candida albicans species. Rev Iberoam Micol 33(4): 248-252.

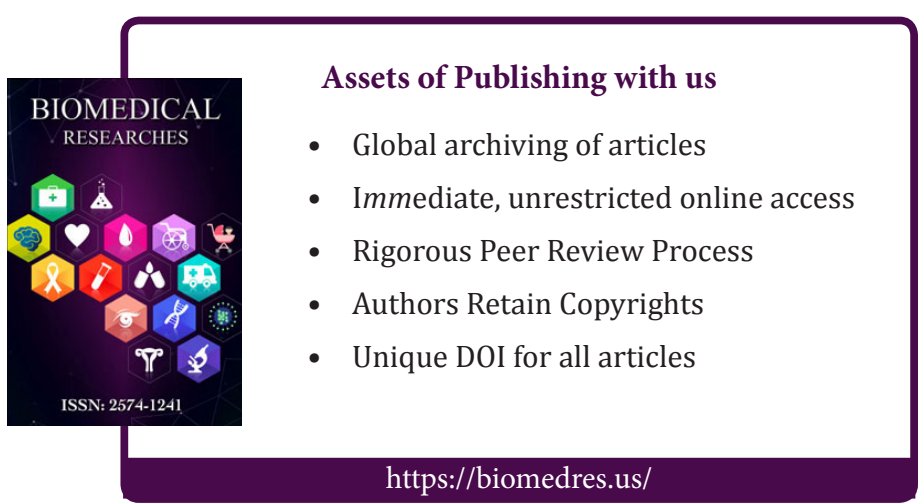

